\title{
Cinco novas espécies de Phaneropteridae brasileiros do gênero Itarissa
}

\author{
S. DE TOLEDO PIZA \\ Escola Superior de Agricultura "Luiz de Queiroz" \\ Universidade de São Paulo
}

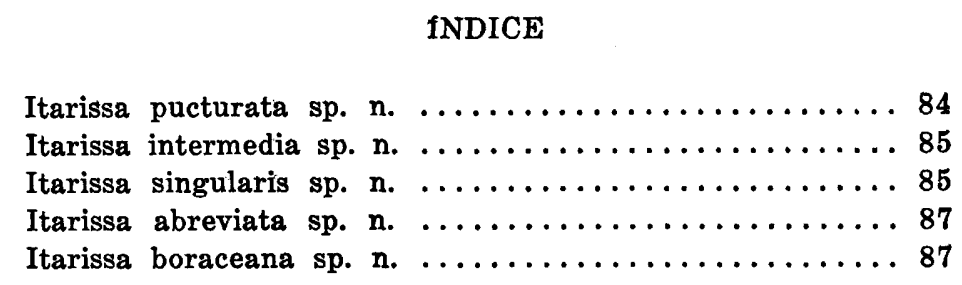


Itarissa puncturata $\mathrm{sp} . \mathrm{n}$.

Mas. Luteo-viridis. Fastigium verticis sulcatum, cum fastigio frontis haud contiguum. Pars basalis antennarum plus minusve castaneo-punctata. Pronotum disco plano, postice in medio sulcato et quam antice paulo latiore, margine antico modice recurvo, postico regulariter rotundato, marginibus lateralibus angulosis, dense minutissime castaneo-nigro puncturatis, lobis deflexis perpendicularibus, evidenter altioribus quam longioribus. Elytra opaca, venis radialibus leviter flexuosis, ramo radiali paulo ante medium oriente, prope insertionem furcato, disco partim castaneo-nigro punctato, vena radiali anteriore ad originem castaneo-punctata, venis transversir plus minusve prominentibus, prope marginem costalem elytrorum precipue, inter series punctorum castaneorum positis, area venae ulnaris usque ad venam dividentem campi horizontalis dense castaneo-punctata. Femora antica disco pronoti vix breviora, subtus ad marginem anteriorem 3-4 spinosa; tibiae anticae castaneo-puncturatae, parte basilari dilatata quam pars distalis angustata multo breviore. Femora intermedia inferne antice 4-5 spinosa; tibiae intermediae castaneo-puncturatae. Femora postica parte basali valde amplia:a, parte apicali angustata castaneopuncturata, inferne antice omnino spinulosa, postice ad partem angustatam tantum; tibiae posticae castaneo-puncturatae. Pars ventralis abdominis castanea. Lamina subgenitalis ad apicem recte truncata, stylis parvulis: Cerci modice sinuosi, ad basim ampliati, deinde usque ad apicem subcylindrici, apice extus castaneo-nigro absolete dentato.

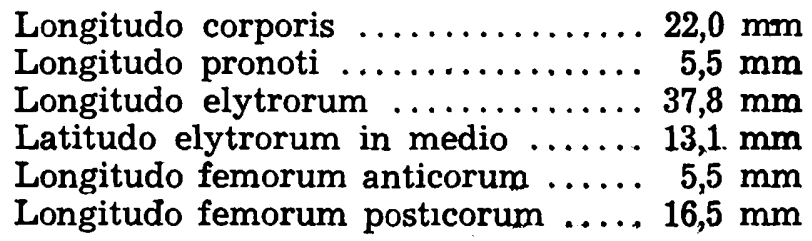

Pátría : Manaus, E. do Amazonas.

Col. : Parko, VII-1941.

Tipo: Um macho pertencente ao Museu Nacional, presentemente com o autor. 


\section{Itarissa intermedia sp. $\mathrm{n}$.}

Mas. Luteo-viridis, nitidus. Caput albescens, fastigio verticis parallelo; obtuso, sulcato, cum fastigio frontis haud contiguo. Pronotum disco antice rotundato, postice plano, margine antico truncato, postico regulariter arcuato et in medio subtilissime emarginato, lobis deflexis evidenter altioribus quam longioribus, rotundatim insertis. Elytra nitida, basi et apice aeque lata, venis radialibus modice flexuosis, ramo radiali angulo acuto in medio inserto, ante medium furcato, ramulo posteriore cum vena ulnari a venula transversa connecto. Vena ulnaris basi recta, venis radialibus appropinquata ac a venulis duabus connecta, parte distali reflexa cum ramo radiali a venula conjuncta. Femora antica disco pronoti evidentissime breviora, inferne ad marginem anteriorem spinis parvulissimis 2 armata. Tibiae anticae parte basali ampliata quam pars distalis breviore. Femora postica subtus spinis 6 utrinque armata. Segmentum abdominale dorsale ultimum ad apicem trucatum. Cerci modice sinuosi, basi quam apex paulo crassiore. Lamina subgenitalis parte basali triangulariter excavata, parte distali convexa, in medio carinata, ad apicem anguste obtusissime angulata.

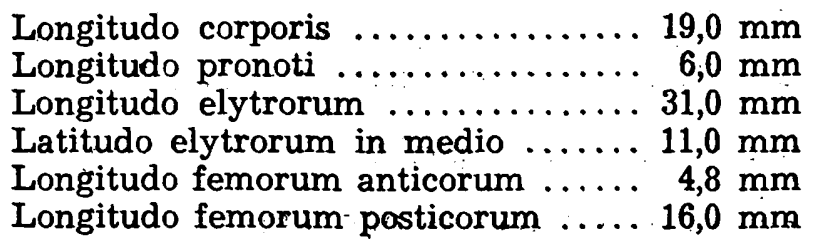

Pátria : Manaus, E. do Amazonas.

Col.: Parko VII-1941.

Tipo: Um macho pertencente ao Museu Nacional, atualmente na coleção do autor.

A presente espécie pareceu-me muito afim de Itarissa coriacea (Pictet). Difere, porém pelo disco do pronoto fortemente convexo na sua porção anterior, pelos lobos laterais evidentemente mais altos do que longos e pelos fêmures anteriores bem mais curtos que o pronoto e com apenas dois pequeninos espinhos no bordo anterior da face ventral.

Itarissa singularis sp. n. (Fig. 1)

Mas. Viridis, nitidus. Fastigium verticis sulcatum. Pronotum disco rotundato, margine antico recto vel vix recurvo, postico regulariter recurvo, utrinque distincte vel obsolete vel 
indistincte longitudinaliter vittato, lobis deflexis rotundatim ininsertis, perpendicularibus, lutescentibus. Elytra basi et apiçe aeque lata. Venae radiales rectae. Ramus radialis a ramis duobus, distictis, haud furcatis, post medium cum vena radiali posteriore independenter connectis, prope extremitates a venula transversa inter se conjunctis, designatus, ramo primo in medio fleuxuoso et cum vena ulnari anteriore a vena transversa conjuncto, ramo secundo recto. Vena ulnaris anterior modice arcuata, a venis radialibus sat remota et cum his a venulis partim absoletis compluribus connecta. Femora antica pronoto breviora, subtus ad marginem anteriorem spinis parvulissimis 2 armata. Pars basalis tibiarum parte distali brevior. Femora postica inferne extus spinis parvulis 6-10 instructa. Segmentum abdominale dorsale ultimum truncatum. Cerci crassi, curvi, versus apicem modice attenuati, apice minutissime dentato. Lamina subgenitalis ad apicem truncata, parte basali triangulariter excavata, parte distali convexa, in medio longitudinaliter carinata.

Longitudo corporis $\ldots \ldots \ldots \ldots \ldots \ldots 21,0 \mathrm{~mm}$

Longitudo pronoti $\ldots \ldots \ldots \ldots \ldots \ldots, 6,0 \mathrm{~mm}$

Longitudo elytrorum .......... $31,5 \mathrm{~mm}$

Latitudo elytrorum in medio .......12,5 $\mathrm{mm}$

Longitudo femorum anticorum ..... 5,2 $\mathrm{mm}$

Longitudo femorum posticorum .... 14,0 mm

Pátria : Ribeirão do Engenho, Vale do Itauna, E. do Espírito Santo.

Col. : Travassos \& Santos, 9-X-1942.

Tipo e parátipos: Três machos pertencentes ao Museu Nacional, atualmente no laboratório do autor.

A nervulação particular das tégminas da presente espécie pode ser atribuida ao fato do ramo radial, que costuma bifurcarse a alguma distância do seu ponto de origem, haver-se ramificado exatamente naquele ponto, sendo que o ramo anterior caminha, até a sua separação, colado à veia radial posterior. (Fig. 1).

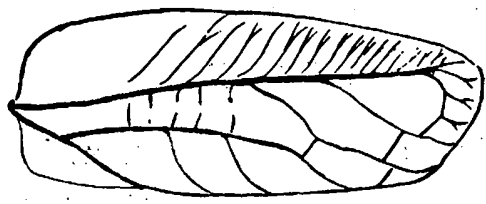

Fig. 1

Itarissa singularis sp. $n$. Tégmina direita 


\section{Itarissa abreviata sp. $\mathrm{n}$.}

Femina. Viridis, nitida. Caput vertice subplano, albidocinereo, fastigio sulcato a fastigio frontis remoto, genis sub oculos albo-cinereis, clypeo labroque nigricantibus. Pronotum abreviatum, disco plano, antice quam postice paulo angustiore, longitudine femorum anticorum vix breviore, margine antico modice recurvo, margine postico rotundato, lobis deflexis rotundatim insertis, perpendicularibus, altioribus quam longioribus, antice modicissime recurvis, postice recurvis, margine inferiore regulariter rotundato. Elytra basin versus modice angustiora, margine postico fortiter arcuato, margine antico vix curvo, venis radialibus leviter flexuosis, campo prae-radiali partim minute reticulato, campo post-radiali minutissime densissime puncturato, ramo radiali angulo acutissimo in medio inserto, prope originem furcato, ramo posteriore cum vena ulnari venulis transversis connecto, vena ulnari parte basali curva, parte distali angulosa. Femora omnia ac tibiae I et II plus minusve castaneo-rufo vittata. Ovipositor latus, compressus, nitidus, fortiter recurvus, disco minutissime puncturato, marginibus crenulatis.

Longitudo corporis $\ldots \ldots \ldots \ldots \ldots, 15,0 \mathrm{~mm}$ Longitudo pronoti $\ldots \ldots \ldots \ldots \ldots \ldots, 4,5 \mathrm{~mm}$ Longitudo elytrorum ........... 27,5 mm Latitudo elytrorum maxima ....... 10,5 mm Longitudo femorum posticorum .... 15,0 mm Longitudo ovipositoris $\ldots \ldots \ldots \ldots \ldots, 4,5 \mathrm{~mm}$

Pátria : Manicoré, E. do Amazonas.

Col. : Parko, IX-1943.

Tipo: Uma fêmea pertencente ao Museu Nacional, presentemente com o autor.

Itarissa boraceana sp. $\mathrm{n}$.

Mas. Magnus, luteus, partim viridis. Caput parvum vertice indistincte castaneo-diluto ornato, fastigio late sulcato, obtuso, cum fastigio fontis haud contiguo. Oculi oblongi, dense castaneo-rufi. Antennae articulis basilaribus plurimis superne castaneo-nigro lineatis. Pronotum disco plano, margine antico in medio vix recurvo, margine postico fortiter rotundato, lobis deflexis rotundatim insertis, subperpendiculari- 
bus, vix altioribus quam longioribus. Elytra coriacea, nitida, apicem versus modice attenuata, densissime puncturato impressa, puncturis complurimis castaneis dispersis vel nonnullas maculas designantibus, angulis humeralibus nigro-nitido signatis, campo dorsali latissimo, maculis castaneis raris in medio, maculis nonnullis seriatis utrinque ornato, vena plicata partim castanea, campo postradiali ad basin castaneo maculato, venis radialibus leviter flexuosis, ramo radiali ante medium oriente, valde ante medium furcato, prope bifurcationem cum vena ulnari anteriore a venula transversa connecto, ramulis paulo divergentibus, inter se a venulis transversis conjunctis, vena ulnari anteriore a basi usque ad ramum primum recta, a margine postico quam a nervis radialibus duplo remotiore, post ramum primum modice arcuata, deinc obliquiter versus marginem posticum directa, cum ramulo postico rami radialis a venula connecta. Femora antica disco pronoti sat breviora, cum femoribus intermediis subtus inermia, apice obscuriora et dense castaneo punctata. Femora postica versus extremitatem densiora, apice precipue ad lobos geniculares castaneo punctata, subtus spinis rubris 11-12 ad marginem externum, 1-2 ad marginem internum armata. Tibiae omnes castaneae, anticae et intermediae densissime castaneo-piceo punctatae, posticae ad basin tantum punctatae. Tibiae anticae superne spina una ad dilatationem basalem et una vel nulla in medio marginis postici praeditae. Tibiae intermediae spinis 1-2 antice, 2-4 postice. Tarsi castanei. Lobi mesonoti trianguloriter, metanoti rotundatim producti. Segmentum anale truncatum. Lamina supraanalis longior quam latior, perpendiculariter inter cercos posita. Cerci graciles, cylindrici, arcuati, ad extremitatem modice compressi et vix incrassati, dente parvo, truncato, castaneo-nigro armati. Lamina subgenitalis brevis, carinata, truncata, stylis gracilibus praedita.

Longitudo corporis ............ 29,0 mm

Longitudo pronoti .............. 8,0 mm

Longitudo elytrorum .......... 49,0 mm

Latitudo elytrorum ad partem latiorem $16,0 \mathrm{~mm}$

Longitudo femorum anticorum ..... 9,0 mm

Longitudo femorum posticorum .... 24,0 mm

Pátria : Salesópolis, Boracea, E. de São Paulo.

Col.: Travassos Filho, Braz, Rabello \& Boherman, 6-11 Março, 1948.

Tipo: Um macho pertencente ao Museu Nacional, presentemente com o autor.

A presente espécie é única pelas dimensões e pela coloracão das tíbias. 